\title{
Persistence of antimuscarinic drug use
}

\author{
Søren Brostrøm • Jesper Hallas
}

Received: 16 July 2008 / Accepted: 2 December 2008 /Published online: 24 December 2008

(C) Springer-Verlag 2008

\begin{abstract}
Purpose Evidence suggests antimuscarinic drugs for the overactive-bladder syndrome only confer modest improvements in quality of life. We wanted to describe the persistence of therapy, including an extended analysis beyond the 1-year follow-up employed in other studies.

Methods All prescriptions for drugs in ATC category G04BD were retrieved for the period 1999-2006 from a regional database with complete capture of all reimbursed prescriptions. Kaplan-Meyer curves were generated for duration of treatment for each substance and analyzed for determinants of termination.

Results With the exception of trospium chloride, all drugs had continuation rates of less than $50 \%$ at 6 months, less than $25 \%$ at 1 year, and less than $10 \%$ at 2 years and longer. Trospium chloride, however, exhibited continuation rates of $46 \%$ at 6 months, $36 \%$ at 1 year, $22 \%$ at 2 years, and $16 \%$ at 3 years.

Conclusions In a setting of socialized medicine, we found higher continuation rates than previously published. Interestingly, we found that one of the older drugs on the market, trospium chloride, had a strikingly longer retention rate than other drugs.
\end{abstract}

\footnotetext{
S. Brostrøm $(\square)$

Department of Obstetrics and Gynecology, Glostrup Hospital, DK-2600 Glostrup, Denmark

e-mail: soren@brostrom.dk

J. Hallas

Research Unit of Clinical Pharmacology,

University of Southern Denmark,

Odense, Denmark
}

Keywords Adherence - Antimuscarinic drugs . Overactive-bladder syndrome · Persistence . Pharmacoepidemiology Pharmacological therapy

\section{Introduction}

Overactive-bladder syndrome (OAB) was redefined in 2002 as "urgency (the complaint of a sudden compelling desire to pass urine which is difficult to defer), with or without urge incontinence, usually with frequency and nocturia" [1]. Approximately one in six adults has symptoms of overactive bladder, with prevalence increasing with age [2]. With the chronic nature of $\mathrm{OAB}$, the potential drug market is huge.

The use of antimuscarinics to treat bladder symptoms was first described half a century ago and has for the last decades been the mainstay of conservative therapy for OAB. Presumably, these drugs work through competitive antagonism of the $\mathrm{M}_{3}$-receptor on the detrusor smooth muscle cell, although an effect on sensory and central pathways cannot be excluded [3, 4]. As muscarinic receptors are widespread in the body, including the central nervous system, eyes, salivary glands, and gastrointestinal tract, concomitant blockade of these functions with antimuscarinic treatment can lead to a diversity of adverse effects.

Antimuscarinic drugs were developed and marketed mainly for gastrointestinal symptoms, until the introduction a decade ago of tolterodine as the first bladder-selective antimuscarinic agent. Since then, a number of new substances and formulations, including long-acting, transdermal, and receptor-selective drugs, have been introduced to an increasingly competitive market. From 2001 to 2005, the number of users in Denmark increased by $59 \%$, with the sales increase driven by the newer and more expensive 
brands. In 2005 the Danish market for antimuscarinics was approximately 100 million DKK, equaling approximately 16 million USD in 2005-rates (http://www.dkma.dk).

The use of antimuscarinic drugs for OAB is supported mostly by 12 -week randomized controlled trials (RCTs) demonstrating statistically significant improvements in symptoms. However, recent trials suggest that the drugs' use only confers modest improvements in quality of life [5]. A metaanalysis showed that while the rate ratio (RR) of improvement was only 1.39 (95\% CI $1.28-1.51)$, there was a tripling of the RR for dry mouth, the most common adverse effect associated with antimuscarinic drug therapy (RR 3.00, 95\% CI 2.70-3.34) [5]. It is not clear whether benefits are sustained during long-term treatment or after cessation of treatment.

Withdrawals during the short-term registration RCTs were few, and the results of long-term or open-label extension studies have also shown very good long-term persistence, e.g., a 1-year continuation rate of $75 \%$ for trospium chloride [6], a 40 -week continuation rate of $81 \%$ for flexible-dose solifenacin [7], a 1-year continuation rate of $71 \%$ for tolterodine extended-release [8], and a 2-year continuation rate of $66 \%$ for darifenacin [9]. However, the external validity of these findings has been questioned by the somewhat more somber findings of real-life prescription refill behavior. In a California Medicaid population, $\mathrm{Yu}$ et al. found 1-year continuation rates of only $12 \%$ [10]. In a younger Medicaid managed-care population, Shaya et al. found even lower estimates, with only $44 \%$ of patients refilling their prescription for tolterodine extended-release after 30 days, and with a 1 -year continuation rate of only $9 \%$ [11]. Similar findings have been reported by others [12-15].

As the studies on $\mathrm{OAB}$ drug persistence in the literature represent selected populations, and there is a lack of data on $\mathrm{OAB}$ drug use in other care settings, we wanted to see if we could replicate these findings in a Danish population characterized by socialized medicine with universal health-care coverage and generous prescription-drug reimbursements. We also wanted to extend our analyses beyond the 6-month or 1-year follow-up employed in other studies, and we wanted to compare differences in persistence between older and newer OAB drugs.

\section{Patients and methods}

\section{Setting}

We used the Odense University Pharmacoepidemiological Database (OPED) as our data source [16]. The OPED has complete capture of all reimbursed prescriptions for citizens of Funen County in Denmark (approx. 470,000 inhabitants), being roughly representative of the national popula- tion of 5.475 million people. The recorded data included a personal identifier, the date of dispensing and codes identifying the dispensed product, the pharmacy, and the prescriber. The quantity and the active substance are expressed by their Anatomic-Therapeutic Chemical (ATC) code and their defined daily dose (DDD), developed by the WHO for the purpose of drug utilization studies (URL: http://www.whocc.no). The dosing instructions and indications on the prescriptions are not recorded. The study was retrospective by design. We retrieved all prescriptions on drugs belonging to ATC code G04BD for the period 19992006. The drugs available for OAB are shown in Table 1.

In order to account for censoring, we also retrieved data on migrations, births, and deaths for the users of $\mathrm{OAB}$ drugs. Our data source was the demographic module of the OPED database. Ethics clearance by regulatory authorities was not required.

\section{Analyses}

We analyzed the use of OAB drugs in 2006 by some of the analytic templates published previously [17]. The generated measures were therapeutic intensity, i.e., the amount measured in DDD per 1,000 inhabitants per day, the incidence rate, the average age of users, and the gender distribution. Results of these analyses are shown in Table 2.

In principle, it is allowed in Denmark to prescribe and dispense drug supply for any duration. Treatment with $\mathrm{OAB}$ drugs can be episodic by nature. Thus, two $\mathrm{OAB}$ drug prescriptions with, e.g., 5 months between them may or may not belong to the same treatment episode. To account for that, we analyzed the waiting-time distributions of prescription refills [18] and frequency distributions of intervals between prescriptions on the same substance for the entire period. We found that prescriptions with more than 120 days between were unlikely to belong to the same treatment episode, and thus we defined a treatment episode as continuing as long as there were fewer than 120 days between prescriptions (data not shown). We performed sensitivity analyses of this assumption by repeating the analyses with the maximum interval set to 100 and 150 days.

The duration of a treatment episode was set to the interval between the first and last prescription of that episode plus a period assigned to the last prescription. The latter was calculated as duration $n_{\text {lastprescription }}=$ $\left[A /\left(A-A_{\text {last }}\right)\right] \times($ Ldate $-F$ date $)$ where: $A=$ total amount of drug dispensed in episode, measured in DDD, $A_{\text {last }}=$ amount of drug dispensed on last dispensing, measured in DDD, Fdate $=$ date of first prescription, and Ldate $=$ date of last prescription.

In brief, this calculation merely assumes that the subject would continue with his usual dose until the amount dispensed with the last prescription had been taken. If only 
Table 1 Antimuscarinic drugs for overactive bladder available in Denmark 1999-2006

\begin{tabular}{|c|c|c|c|c|c|c|}
\hline Substance & $\begin{array}{l}\text { Trade } \\
\text { name(s) }\end{array}$ & ATC code & $\begin{array}{l}\text { Defined daily } \\
\text { dose }(\mathrm{mg})\end{array}$ & Marketing date & $\begin{array}{l}\text { Retail price per day } \\
\text { (EUR) as of } 6 \\
\text { October } 2008\end{array}$ & Comments \\
\hline Emepronium & Cetiprin Novum & G04BD01 & 800 & & & $\begin{array}{l}\text { Withdrawn from market } \\
5 \text { July } 2004\end{array}$ \\
\hline Flavoxate & Urispadol & G04BD02 & 800 & & 2.35 & \\
\hline Oxybutinin & Kentera & G04BD04 & 3.9 & 20 June 2005 & 2.13 & Transdermal formulation only \\
\hline Tolterodine & Detrusitol & G04BD07 & 4 & $\begin{array}{l}\text { Immediate-release } \\
\text { marketed from } \\
18 \text { May } 1998 \text { to } 1 \\
\text { April } 2002 \text {. } \\
\text { Extended-release } \\
\text { marketed from } \\
10 \text { December } 2001\end{array}$ & 2.26 & $\begin{array}{l}2 \mathrm{mg} \text { marketed for } \\
\text { patients with renal or } \\
\text { hepatic impairment }\end{array}$ \\
\hline Solifenacin & Vesicare & G04BD08 & 5 & 16 August 2004 & 1.86 & $\begin{array}{l}5 \text { and } 10 \mathrm{mg} \text { marketed } \\
\text { with recommendations } \\
\text { for dose titration }\end{array}$ \\
\hline $\begin{array}{r}\text { Trospium } \\
\text { chloride }\end{array}$ & $\begin{array}{l}\text { Spasmo-lyt, } \\
\text { Spasmoplex }\end{array}$ & G04BD09 & 40 & 12 November 2001 & 1.21 & $\begin{array}{l}\text { ATC code changed } 1 \\
\text { January } 2004 \text {, was A03AB20 }\end{array}$ \\
\hline Darifenacin & Emselex & G04BD10 & 7.5 & 10 October 2005 & 1.86 & $\begin{array}{l}7.5 \text { and } 15 \mathrm{mg} \text { marketed } \\
\text { with recommendations for } \\
\text { dose titration }\end{array}$ \\
\hline
\end{tabular}

one prescription occurred, the period assigned was equal to the dispensed quantity divided by the average daily quantity consumed by subjects who had redeemed more than one prescription.

We generated Kaplan-Meyer curves for each of the substances. For all individual users, only the first treatment episode with a given substance was analyzed, but individuals could contribute with more than one episode if they used more than one substance. Followup was censored at the end of the study period or at the subject's death or emigration, if any. Survival analyses were conducted on a patient-episode basis over the time period, thus patients who continued taking a particular drug for up to 7 years with no more than 120-day gaps were regarded as experiencing single-treatment episodes.

Finally, we analyzed determinants of termination of $\mathrm{OAB}$ drug treatment, using the Cox-proportional hazard method [19]. Independent variables were age, gender, a history of prior use of another OAB drug, use of antidiabetics, the estimated dose, and the choice of drug. The statistical software package STATA was used.

\section{Results}

Through 2006, we found 11,081 prescriptions dispensed to 2,477 persons, of whom 1,641 were women $(66.2 \%)$ and 836 men $(33.8 \%)$. Their average age was 69.0 years for men and 68.0 for women.

The characteristics of use for each of the products are described in Table 2. The bulk of the market was carried by tolterodine, solifenacin, and trospium. After little more than 1 year on the market, oxybutinin TDS and darifenacin had found few users. Users of flavoxate differed from the rest of the population in being older and more of them were male.

Table 2 Characteristics of use for antimuscarinic drugs for overactive bladder

\begin{tabular}{|c|c|c|c|c|c|}
\hline Substance & Number of users & Men $(\%)$ & Average age (years) & Number of prescriptions & Quantity DDD/user (mg) \\
\hline Flavoxate (G04BD02) & 21 & $9(42.9)$ & 74.1 & 110 & 150 \\
\hline Oxybutynin (G04BD04) & 48 & $9(18.8)$ & 61.4 & 140 & 27 \\
\hline Tolterodine (G04BD07) & 1478 & $505(34.2)$ & 69.8 & 6692 & 120 \\
\hline Solifenacin (G04BD08) & 774 & $257(33.2)$ & 66.3 & 2925 & 193 \\
\hline Trospium (G04BD09) & 271 & $96(35.4)$ & 67.0 & 1087 & 137 \\
\hline Darifenacin (G04BD10) & 52 & $16(30.8)$ & 67.5 & 127 & 93 \\
\hline
\end{tabular}

Data from Funen County, Denmark 2006 


\section{Kaplan-Meyer graph of persistence with antimuscarinic drugs}

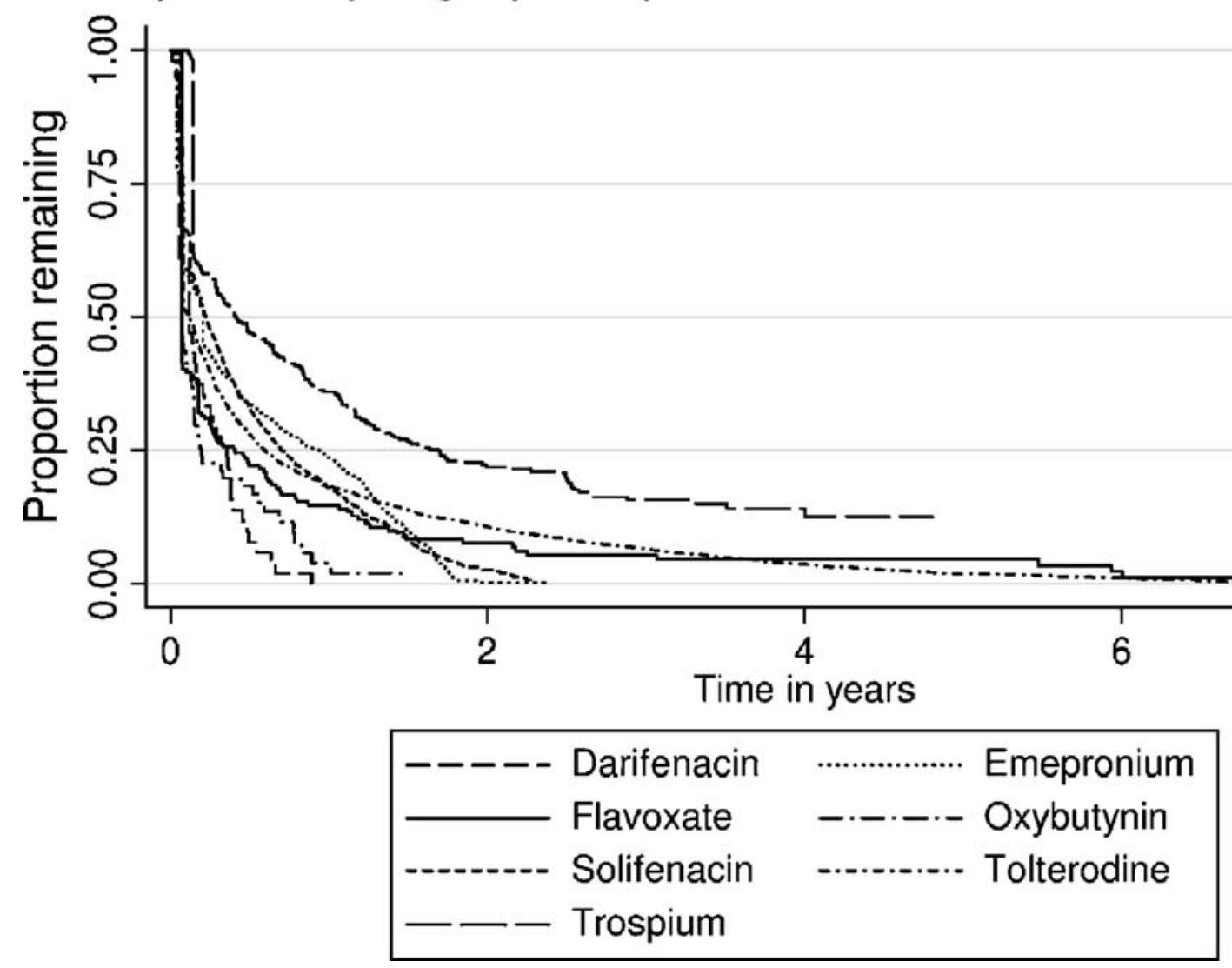

Fig. 1 Kaplan-Meyer plots of persistence with antimuscarinic drugs for overactive bladder. Proportion of treatment episodes remaining over time. Data from Funen County, Denmark 1999-2006

Retention was described by Kaplan-Mayer analyses (Fig. 1). With the exception of trospium chloride, all $\mathrm{OAB}$ drugs had continuation rates of less than $50 \%$ at 6 months, less than $25 \%$ at 1 year, and less than $10 \%$ at 2 years and longer. Trospium chloride, however, exhibited continuation rates of $46 \%$ at 6 months, $36 \%$ at 1 year, $22 \%$ at 2 years, and $16 \%$ at 3 years.

Predictors of treatment discontinuation are shown in Table 3. Retention was longer among women than men, longer among the old than among the young, longer with higher doses, and longer with past experience with other drugs for $\mathrm{OAB}$. There was a significantly longer retention with trospium than with all other drugs $[\mathrm{HR}=0.65(95 \% \mathrm{CI}$ 0.57-0.74) for comparison with tolterodine] after adjustment for potential confounders.

To test the sensitivity of our analyses to assumptions about maximum allowed interval between prescriptions in the same treatment course, we analyzed the data with values set to 100 , 120, and 150 days. Estimated Kaplan-Meyer durations corresponding to $25 \%$ of the users still remaining for tolterodine were $0.49,0.59$, and 0.71 years respectively.

\section{Discussion}

Surprisingly, we found much higher persistence rates than previously reported in the literature, with our 1-year persistence rates comparable to the 30-day persistence rates found by others $[10,11,14]$. The health-care setting with easy access and generous reimbursements might also explain the higher persistence. Due to national regulations, the dispensing of free drug samples by doctors is severely restricted in Denmark. Most patients entered in our study had probably paid for their first prescription themselves, thus likely excluding those reluctant to pay anything at all. Looking at the Kaplan-Meier estimates in the studies by $\mathrm{Yu}$ et al. and Shaya et al., we are somewhat surprised by the large number redeeming only one prescription $[10,11]$. This finding might be explained by the lack of patient incentive to continue an expensive treatment.

The nature of the doctor-patient interaction could contribute to the differing persistence. In comparison, Bourgault et al. found 1- and 3-year persistence rates of 66 and 53\% for newer antihypertensives [20]. With this 
Table 3 Determinants of treatment cessation for antimuscarinic drugs for overactive bladder

\begin{tabular}{ll}
\hline Characteristic & Hazard ratio $(95 \%$ confidence interval) \\
\hline Gender & \\
Female & 1.00 ref \\
Male & $1.19(1.14-1.24)$ \\
Age & \\
$\leq 59$ & 1.00 ref \\
$60-79$ & $0.88(0.84-0.93)$ \\
$\geq 80$ & $0.85(0.80-0.91)$ \\
Dose & \\
$\leq 0.7$ DDD per day & 1.00 ref \\
$>0.7$ DDD per day & $0.77(0.73-0.82)$ \\
Drug choice & \\
Tolterodine & 1.00 ref \\
Solifenacin & $1.39(1.29-1.50)$ \\
Trospium & $0.65(0.57-0.74)$ \\
Emepronium & $1.21(1.10-1.32)$ \\
Others & $1.82(1.61-2.07)$ \\
Prior use of OAB drugs & \\
No & 1.00 ref \\
Yes & $0.71(0.66-0.76)$ \\
Prior use of antidiabetics & \\
No & 1.00 ref \\
Yes & $0.96(0.88-1.05)$ \\
\hline
\end{tabular}

Cox proportional hazard regression analysis

class of drugs, patients are probably counseled extensively on the potential health benefits of long-term usage, and follow-up visits are scheduled to assess effect and adherence of treatment. It is interesting to compare the continuation rates of drugs such as antihypertensives or statins, with a perceived protective effect on lifethreatening diseases, to that of drugs such as antimuscarinics, which merely offer symptomatic relief. While OAB is perceived as a chronic disease, that may in fact be a too-broad definition, including non-specific, remitting, and non-chronic symptomatology. Two studies have found that a sizeable proportion of patients on antimuscarinics stopped taking the drugs because they "learned to get by" without drugs, had spontaneous symptom resolution, or were "cured" [21, 22]. Our choice of allowing a 120-day gap in treatment episodes could also have contributed to the particularly high persistence found in our study. Other studies have allowed smaller gaps $[10,11,14]$.

Other studies have shown better continuation rates with once-daily dosing $[10,11]$. We failed to replicate this finding in the present study, as trospium chloride, prescribed twice daily on an empty stomach, had much better continuation rates than, e.g., tolterodine or solifenacin, which are prescribed without these caveats.

Cost could certainly be a factor as trospium chloride is available as a generic formulation and is only about half the price of the newer drugs on the Danish market. All drugs in the present study are reimbursed equally, on a sliding scale from 50 to $85 \%$ of retail price, depending on consumption. Also, there are no local or national formularies favoring one drug over another.

Lack of efficacy and side effects are the major patientreported reasons for discontinuation of OAB drugs, with drug costs ranking lower $[14,15,21,22]$. Due to the variable pharmacology of the seven substances tested in our study, efficacy and side-effect profiles could be expected to differ. Interestingly, we found that one of the older drugs on the market, trospium chloride, had longer retention than solifenacin, a newcomer. Solifenacin is an $\mathrm{M}_{3}$-receptor-selective antimuscarinic being marketed with recommendations for dose titration. In an RCT, a flexible-dosage regimen of solifenacin had a higher prevalence of dry mouth and constipation than a fixed dose of tolterodine [23]. While presumably the $\mathrm{M}_{3}$-selectivity should infer greater bladder efficacy, it could also cause greater gastrointestinal side effects.

Tolterodine, darifenacin, solifenacin, and oxybutynin all undergo extensive hepatic metabolism. Trospium does not and is eliminated as an unchanged drug. Thus it has a lower potential for drug-drug interactions and is a safer treatment option for $\mathrm{OAB}$ in the context of polypharmacy, a significant concern in older patients.

Zhou et al. found much higher persistence for tolterodine than flavoxate [13], and though we also find a slightly poorer persistence of flavoxate compared to tolterodine, the difference is not of the same magnitude. Our findings of longer retention in women, the elderly, and prior $\mathrm{OAB}$ drug users replicates other studies $[10,11]$, although in contrast to Boccuzzi et al. we found no influence of prior use of antidiabetics [24].

Differences in physician choice could certainly be a factor in the seemingly robust use of trospium chloride. Trospium chloride could be the drug of choice in populations with a higher persistence, e.g., older patients or prior users of antimuscarinics. Also, the longer a drug has been on the market, the more longterm users it would have acquired, which would tend to favor tolterodine and tropsium chloride in the present study.

\section{Conclusions}

In a setting of socialized medicine with universal health-care coverage and generous drug reimbursements, we found higher continuation rates of $\mathrm{OAB}$ drugs than previously published for U.S. Medicaid managed-care settings, but lower rates than reported in trials. We also found that one of the older drugs on the market, 
trospium chloride, had a strikingly longer retention than the other drugs for $\mathrm{OAB}$. We believe that measurements of persistence of OAB drug therapy in real-life settings can complement existing evidence on drug efficacy and tolerability in assessing and comparing the clinical performance of the available drugs on the market.

\section{References}

1. Abrams P, Cardozo L, Fall M, Griffiths D, Rosier P, Ulmsten U, van Kerrebroeck P, Victor A, Wein A (2002) The standardisation of terminology in lower urinary tract function: report from the Standardisation Sub-committee of the International Continence Society. Neurourol Urodyn 21:167-178

2. Milsom I, Abrams P, Cardozo L, Roberts RG, Thuroff J, Wein AJ (2001) How widespread are the symptoms of an overactive bladder and how are they managed? A population-based prevalence study. BJU Int 87:760-766 (Erratum in: BJU Int 2001; 88:807)

3. Finney SM, Andersson KE, Gillespie JI, Stewart LH (2006) Antimuscarinic drugs in detrusor overactivity and the overactive bladder syndrome: motor or sensory actions. BJU Int 98:503-507

4. Abrams P, Andersson KE, Buccafusco JJ, Chapple C, de Groat WC, Fryer AD, Kay G, Laties A, Nathanson NM, Pasricha PJ, Wein AJ (2006) Muscarinic receptors: their distribution and function in body systems, and the implications for treating overactive bladder. Br J Pharmacol 148:565-578

5. Nabi G, Cody JD, Ellis G, Herbison P, Hay-Smith J (2006) Anticholinergic drugs versus placebo for overactive bladder syndrome in adults. Cochrane Database Syst Rev 4:CD003781

6. Halaska M, Ralph G, Wiedemann A, Primus G, Ballering-Bruhl B, Hofner K, Jonas U (2003) Controlled, double-blind, multicentre clinical trial to investigate long-term tolerability and efficacy of trospium chloride in patients with detrusor instability. World J Urol 20:392-399

7. Haab F, Cardozo L, Chapple C, Ridder AM (2005) Long-term open-label solifenacin treatment associated with persistence with therapy in patients with overactive bladder syndrome. Eur Urol 47:376-384

8. Kreder K, Mayne C, Jonas U (2002) Long-term safety, tolerability and efficacy of extended-release tolterodine in the treatment of overactive bladder. Eur Urol 41:588-595

9. Haab F, Corcos J, Siami P, Glavind K, Dwyer P, Steel M, Kawakami F, Lheritier K, Steers WD (2006) Long-term treatment with darifenacin for overactive bladder: results of a 2-year, openlabel extension study. BJU Int 98:1025-1032
10. Yu YF, Nichol MB, Yu AP, Ahn J (2005) Persistence and adherence of medications for chronic overactive bladder/urinary incontinence in the California Medicaid program. Value Health $8: 495-505$

11. Shaya FT, Blume S, Gu A, Zyczynski T, Jumadilova Z (2005) Persistence with overactive bladder pharmacotherapy in a Medicaid population. Am J Managed Care 11:S121-S129

12. Chui MA (2004) Patient persistence with medication for overactive bladder. Value Health 7:366

13. Zhou Z, Barr C, Torigoe Y, Williamson T (2001) Persistence of therapy with drugs for overactive bladder. Value Health 4:161

14. Kelleher CJ, Cardozo LD, Khullar V, Salvatore S (1997) A medium-term analysis of the subjective efficacy of treatment for women with detrusor instability and low bladder compliance. Br J Obstet Gynaecol 104:988-993

15. Saks EK, Northington G, Gopal M, Arya L (2006) Adherence to anti-cholinergic medications in women with urge incontinence. Int Urogyn J 7:5398

16. Gaist D, Sørensen HT, Hallas J (1997) The Danish prescription registers. Dan Med Bull 44:445-448

17. Hallas J, Stovring H (2006) Templates for analysis of individuallevel prescription data. Basic Clin Pharmacol Toxicol 98:260-265

18. Hallas J, Gaist D, Bjerrum L (1997) The waiting-time distribution for prescription drugs. Epidemiology 8:666-670

19. Cox DR (1972) Regression models and life tables. J R Stat Soc B $34: 187-220$

20. Bourgault C, Sénécal M, Brisson M, Marentette MA, Grégoire J-P (2005) Persistence and discontinuation patterns of antihypertensive therapy among newly treated patients: a population-based study. J Human Hypertens 19:607-613

21. Pesce F, Rubilotta E, D’Amico A, Siracusano S, Righetti R, Celia A, Tiberio A, Artibani W (2003) Long-term anticholinergic therapy: duration and causes of discontinuation. Abstract 304 [poster]. International Continence Society 2003, 25-27 August 2003, Paris, France

22. Brubaker L, Nichol M, Fanning K, Becker R, Jumadilova Z, Benner J (2006) Patient-reported reasons for discontinuing overactive bladder $(\mathrm{OAB})$ medications. Neurourol Urodyn 25:614

23. Chapple CR, Martinez-Garcia R, Selvaggi L, Toozs-Hobson P, Warnack W, Drogendijk T, Wright DM, Bolodeoku J (2005) A comparison of the efficacy and tolerability of solifenacin succinate and extended release tolterodine at treating overactive bladder syndrome: results of the STAR trial. Eur Urol 48:464-470

24. Boccuzzi SJ, Le TK, Wogen J, Williamson T (2002) Utilization patterns associated with tolterodine immediate release versus oxybutinin in the management of urinary incontinence (UI). Value Health 5:274 